\title{
Uplift around the geothermal power plant of Landau (Germany) as observed by InSAR monitoring
}

\author{
Christine Heimlich*, Noël Gourmelen², Frédéric Masson ${ }^{1}$, Jean Schmittbuhl', Sang-Wan Kim³ and Jérôme Azzola ${ }^{4}$
}

\author{
* Correspondence: \\ christine.heimlich@unistra.fr \\ ${ }^{1}$ IPGS-UMR 7516, CNRS-Université \\ de Strasbourg, 5 rue René \\ Descartes, Strasbourg 67084, France \\ Full list of author information is \\ available at the end of the article
}

\begin{abstract}
Background: Several centimetres of uplift were observed extending over a square-kilometre area around the geothermal site of Landau, Germany.

Methods: This observation is based on the interpretation of a geodetic survey using radar satellite images of the Upper Rhine Graben recorded between April 2012 and April 2014. Observations are based on two data processing methods for synthetic aperture radar acquisitions: synthetic aperture radar interferometry (InSAR) and permanent scatterer InSAR (PS-InSAR) monitoring.

Results: The inferred time evolution shows that the displacement began in July 2013 and that the displacement rate reaches its maximum (about $16 \mathrm{~cm} /$ year) during the summer period (from July to September 2013). We observe a surface displacement of $3.5 \mathrm{~cm}$ during this period.
\end{abstract}

Conclusions: A preliminary inversion of the source of the deformation based on a simple elastic model of a buried cavity suggests that a significant injection of fluid occurred at a depth of approximately $450 \mathrm{~m}$ below the geothermal plant.

Keywords: PS-InSAR; InSAR; Surface displacement; Geothermy

\section{Background}

The Upper Rhine Graben has high potential for deep geothermal energy owing to a high temperature gradient combined with a large fluid source (Pribnow and Schellschmidt 2000). Since 1987, a geothermal research laboratory in the French area of the Upper Rhine Graben, the GEIE of Soultz-sous-Forêts (France), has provided considerable knowledge on deep geothermal energy and its production (Gerard et al. 2006; Genter et al. 2010). One development of lessons learned from Soultz-sous-Forêts is the geothermal power plant of Landau, which is located south of the city of Landau and $35 \mathrm{~km}$ northeast of Soultz-sous-Forêts. The power plant has a doublet configuration in which one well is the production well and the second well is used for the geothermal water reinjection. The production well was bored in 2005 to 3,300 $\mathrm{m}$ deep. The well deviates to the west, with an inclination as high as $29^{\circ}$. The reinjection well was bored in 2006 to $3,170 \mathrm{~m}$ deep, with an inclination as high as $25^{\circ}$ to the east. The power plant had been running successfully since 2007 , but the production stopped on 14 March 2014, when a major surface deformation was observed in the vicinity of the plant. A link between the geothermal production and the surface displacement was established (www.bodenhebungen-landau.de).

\section{Springer}

(c) 2015 Heimlich et al.; licensee Springer. This is an open access article distributed under the terms of the Creative Commons Attribution License (http://creativecommons.org/licenses/by/4.0), which permits unrestricted use, distribution, and reproduction in any medium, provided the original work is properly credited. The Creative Commons Public Domain Dedication waiver (http:// creativecommons.org/publicdomain/zero/1.0/) applies to the data made available in this article, unless otherwise stated. 
To understand the geophysical processes that might be responsible for this surface deformation, a regional geodetic survey will be important. Indeed, previous geodetic analyses of geothermal regions have already been performed and have shown that vertical and horizontal displacements have been caused by geothermal exploitation (e.g. Massonnet et al. 1997; Carnec and Fabriol 1999; Fialko and Simons 2000; Nishijima et al. 2005; Glowacka et al. 2010; Jeanne et al. 2014). Note that surface displacement can also be observed during the drilling phase (Lubitz et al. 2013).

In this study, we present results from recent geodetic radar surveys using synthetic aperture radar (SAR) images. The images cover the Landau region from April 2012 to April 2014. First, we describe the methods in the Methods section, i.e. SAR interferometry (InSAR) and permanent scatterer InSAR (PS-InSAR) monitoring. In the Results section, we present a map of the surface displacement around the geothermal plant of Landau and discuss the evolution of the displacement along specific geographical profiles. Finally, in the Discussion section, we discuss our results, we compare our InSAR results with levelling measurements and introduce a simple model that provides a preliminary inversion of the observed surface deformation. The Conclusion section is devoted to conclusions.

\section{Methods}

\section{InSAR and PS-InSAR}

Our dataset consists of 57 SAR acquisitions from the TerraSAR-X satellite of the German Space Agency (DLR) from April 2012 to April 2014, with a repeat time between successive acquisitions of 11 days. Some acquisitions were not, however, performed by the DLR; thus, measurement gaps of up to 55 days occurred at the end of the summer of 2013. The X-band (3.1-cm wavelength) SAR images are acquired in descending orbit with an incidence angle of $21^{\circ}$ and a 2 -m ground resolution.

Surface displacement is measured by exploiting the phase variation between consecutive SAR measurements using both conventional InSAR (Gabriel et al. 1989; Massonnet and Feigl 1998; Rosen et al. 2000; Hanssen 2001) and PS-InSAR (Usai 1997; Ferretti et al. 2001) techniques. InSAR is sensitive to the change in distance between the ground and the satellite in the line of sight (LOS) direction and is, for a spaceborne SAR system with a small look angle such as used here, mainly sensitive to vertical ground displacement and, to a lesser extent, to horizontal ground displacement. Conventional InSAR has the advantage of maximising the spatial coherence for short temporal baselines but is limited by surface coherence, and PS-InSAR has the advantage of resolving deformation in regions of low coherence, such as the region surrounding the geothermal plant in Landau.

InSAR techniques have been applied to study surface deformation related to the earthquake cycle (Massonnet et al. 1993; Zebker et al. 1994; Fialko et al. 2005; Burgmann et al. 2006; Peltzer et al. 2001), magmatic activity (Amelung et al. 2000; Pritchard and Simons 2002; Hooper et al. 2004; Wright et al. 2006; Wicks et al. 2006; Doubre and Peltzer 2007; Biggs et al. 2009) and subsurface reservoirs (Jonsson et al. 1998; Massonnet et al. 1997; Amelung et al. 1999; Fialko and Simons 2000; Bawden et al. 2001; Newman et al. 2006; Gourmelen et al. 2007; Vasco et al. 2008).

For the PS-InSAR approach, we use algorithms developed at Sejong University (Kim et al. 2010) following the procedure described by Ferretti et al. (2001). A stack of SAR 
images coregistered to a common master is used to compute a stack of interferograms from which orbital and topographical phase components are removed using orbit information provided by the DLR and the SRTM DEM, respectively (Farr et al. 2007). Permanent scatterers are then selected based on the temporal characteristics of the measured signal. The phase of the permanent scatterers is then spatially and temporally identified prior to evaluating the DEM errors, the atmospheric phase screen, the surface deformation time series and the mean velocity from linear regression of the deformation time series at each persistent scatterer (PS).

\section{Levelling}

The local government produces regular levelling measurements in Landau (the measurements are published at www.bodenhebungen-landau.de). Some points have been measured since 1993, but most points have only been measured since October 2013. The levelling measurements provide information on the vertical movement over time. Since October 2013, the city of Landau has completed the levelling measurements with Global Navigation Satellite System (GNSS) measurements of horizontal displacement at sites close to the geothermal power plant. We selected the levelling measurement sites that are collocated with PS-InSAR pixels to compare both results.

\section{Results}

Figure 1A shows the PS-InSAR mean velocity in the area of Landau between 8 July 2013 and 9 April 2014. Despite a lack of information where the temporal coherence is too weak (black domains), we observe a quasi-circular displacement pattern south of Landau centred on the geothermal plant of Landau (white circle, Figure 1A). The average uplift rate reaches $5 \mathrm{~cm} /$ year at the plant site. A highly coherent short-term interferogram between 24 February 2014 and 7 March 2014 (Figure 1B) clearly shows the spatial relationship between the deformation field and the location of the geothermal plant. The radius of the whole area affected by the surface deformation between April 2012 and April 2014 centred on the power plant extends from 800 to 1,000 m. We also observe a larger north-south elongated area of moderate uplift north of Landau close to the village of Nussdorf (Figure 1A - point A), where oil exploitation is ongoing.

A north-south profile extending from the oil fields located north of Landau to the geothermal power plant south of Landau (Figure 2; Figure 1 for the locations of the profiles) shows the temporal and spatial evolution of the cumulative displacement. Details on the evolution at six locations (A, B, C, D, E and F from north to south) along the N-S profile are plotted in Figure 3. Figure 2 displays two displacement profiles along the west-east direction: one through the centre of the city of Landau (crossing the N-S profile close to point D) and one close to the geothermal plant (crossing the $\mathrm{N}-\mathrm{S}$ profile at point $\mathrm{F}$ ).

\section{High-rate uplift from July 2013 around the Landau geothermal plant}

Figures 2 and 3F do not show significant displacement surrounding the geothermal plant from April 2012 to July 2013. The increase in the displacement rate was initiated at the beginning of July 2013 in the vicinity of the geothermal power plant. After July 2013, the displacement exhibited a major rate change that is clearly visible in the time 
A

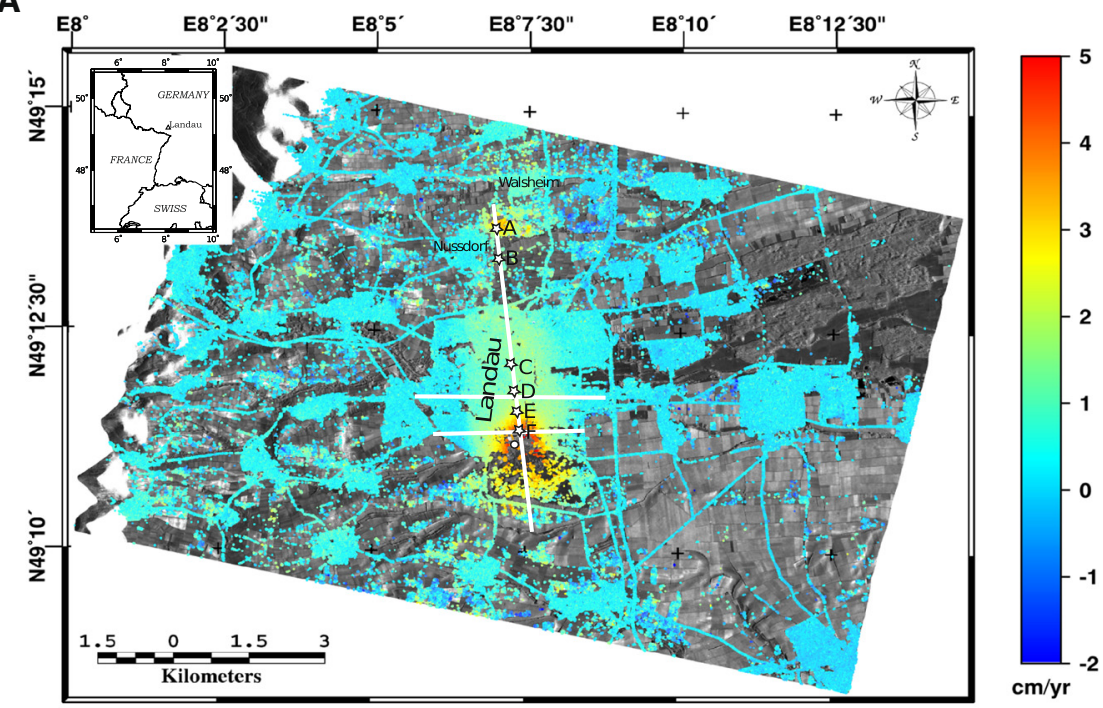

B

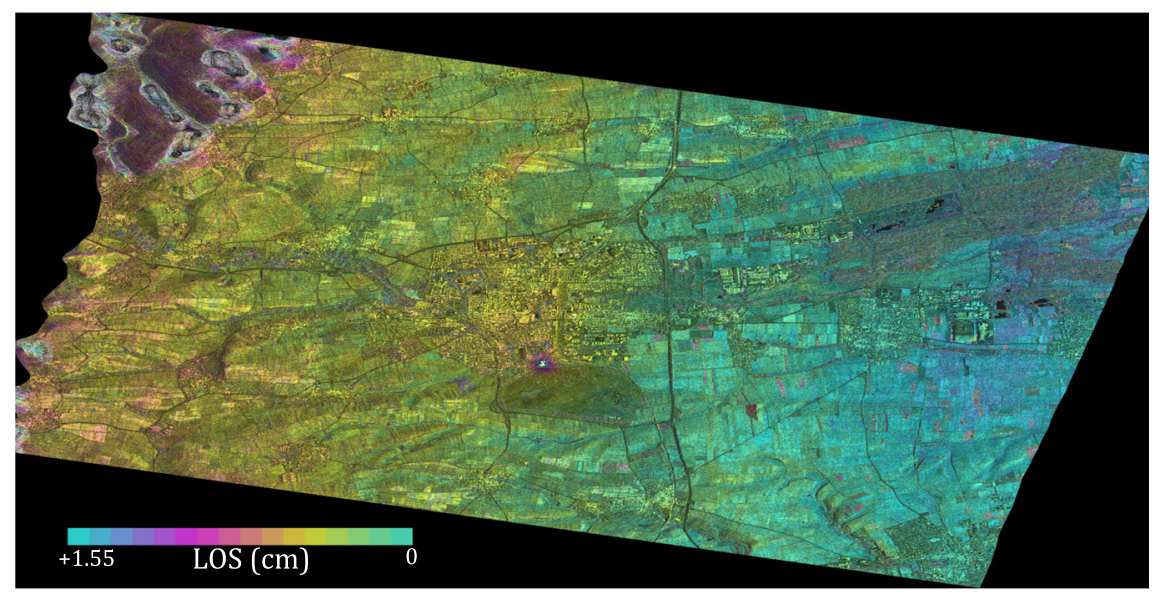

Figure 1 Map of the mean displacement velocity and interferogram showing uplift in south Landau. (A) Map of the mean displacement velocity ( $\mathrm{cm} /$ year) over Landau. Mean displacement velocity ( $\mathrm{cm} /$ year) in the LOS direction (positive towards the satellite) over the city of Landau (Germany) between 8 July 2013 and 9 April 2014 as obtained from the PS-InSAR results. White lines: profiles of Figure 2. White stars: location of the time series of Figure 3. White circle: location of the power plant. (B) Interferogram showing uplift in south Landau. Uplift centred on the geothermal power plant between 24 February 2014 and 7 March 2014 as obtained from the InSAR analysis. The white cross marks the power plant location. One colour cycle corresponds to a deformation of $1.55 \mathrm{~cm}$ in the LOS direction (positive towards the satellite). Here, the displacement reaches a maximum of $2 \mathrm{~cm}$.

series (Figure 3F). The displacement amplitude reached $2.4 \mathrm{~cm}$ between 30 July 2013 (lower purple curve) and 23 September 2013 (middle black curve). During this period, the uplift reached more than half of the total uplift that had occurred since July 2013. The profiles of the displacement show a clear maximum at point $F$, i.e. the intersection of the profiles at $0.29 \mathrm{~km}$ from the power plant (Figures 1 and 2). Note that the location of the maximum displacement is slightly shifted from the surface location of the geothermal plant in the direction of the injection well (to the east). 


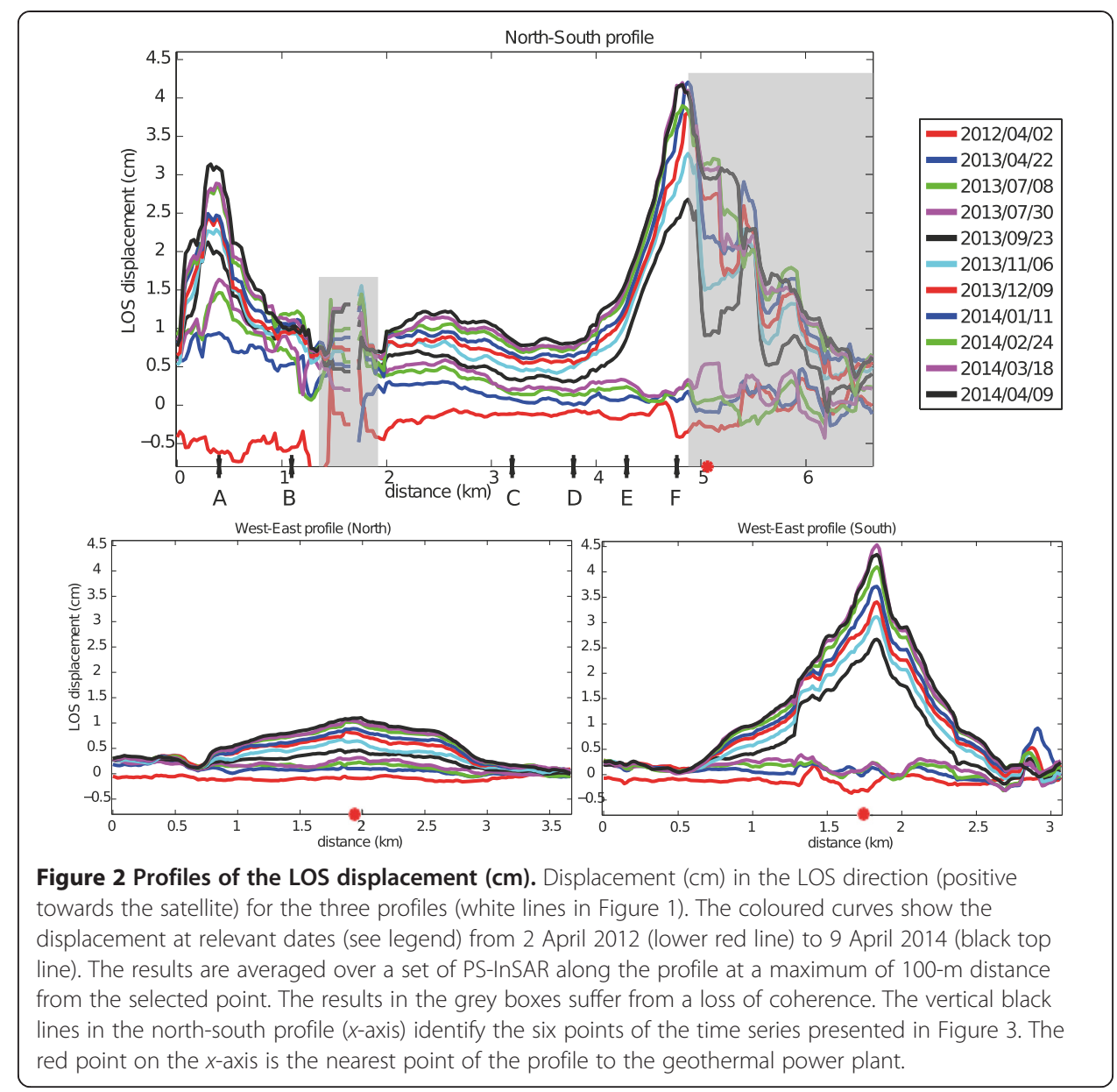

\section{Displacement after March 2014 in the vicinity of the geothermal plant location}

In the southern west-east profile in Figure 2, we can see a decrease in the displacement approximately $100 \mathrm{~m}$ east of the nearest point of the geothermal plant location between 18 March 2014 (purple curve) and 9 April 2014 (black curve). We can also see this change in the displacement direction in the north-south profile. However, the results are affected by the spatial decorrelation in the pixel in the profile, so the results are less constrained than in the west-east profiles.

The inversion of polarity of the deformation is more visible in the levelling results (Figure 4), where the time series extends a month later (until May 2014) than the PS time series, particularly at the sites closest to the geothermal plant (sites 5 and 6).

\section{Continuous uplift in the north during 2012 to 2013}

North of Landau, we observe a region of continuous uplift that culminates in the vicinity of the village of Nussdorf (Figure 1). The uplift (Figures 2 and 3A) has an average rate of $1.5 \mathrm{~cm} /$ year. The area affected by this continuous displacement extends from point A to $\mathrm{C}$, over a distance of $3 \mathrm{~km}$, and reaches the centre of the city of Landau. The amplitude decreases from north to south, where the maximum displacement is at point $\mathrm{A}$ at a distance of $0.3 \mathrm{~km}$ from the northern limit of our profile and the minimum displacement along the profile is close to point $\mathrm{C}$. On the regional map (Figure 1A), the uplift is maximal east of the profile between Nussdorf and Walsheim at the oil fields. 


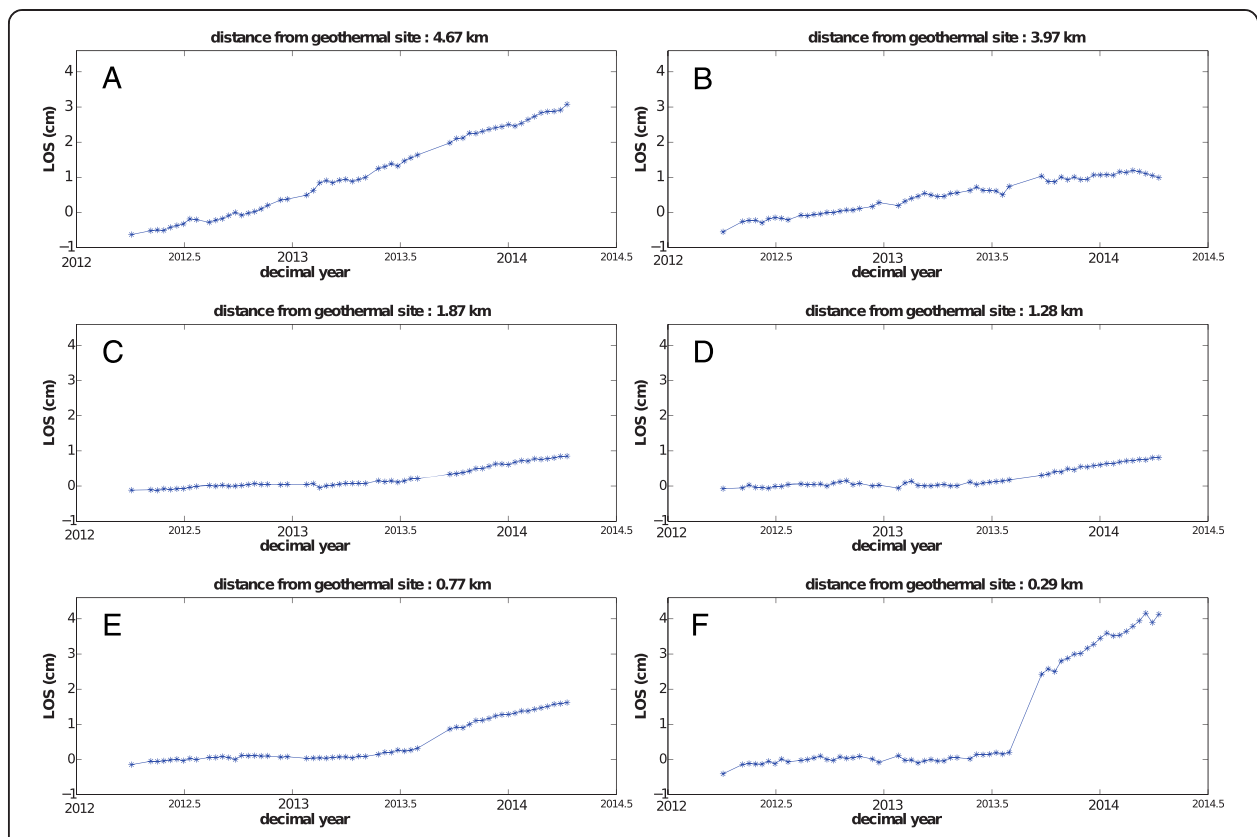

Figure 3 Time series from the north-south profile. A, B, C, D, E, F: time series corresponding to the points located Figures 1 and 2 from the north (A) to close to the geothermal site location (F). Each time series represents the LOS displacement towards the satellite $(\mathrm{cm})$.

\section{Discussion}

\section{PS-InSAR}

We observe two patterns of uplift: one in the north and one in the south. Point $\mathrm{C}$ (Figures 1 and 2) seems to be at the transition between the two strain fields: the southern field related to the geothermal plant that was initiated in July 2013 and the northern field related to the oil exploitation that was initiated before April 2012, i.e. the beginning of our InSAR survey. Indeed, point C (see Figure 3C) exhibits both a slow, continuous displacement increase at the beginning of the monitoring in 2012 and then a clear acceleration in July 2013 to a higher rate that is synchronous with the onset of the geothermal strain. Therefore, the geothermal strain field is significantly distinct from the regional strain.

The maximum PS-InSAR displacement for points in the proximity of the geothermal plant for the July 2013 to March 2014 time period reaches $4 \mathrm{~cm}$ in the LOS direction in the north-south profile and $4.2 \mathrm{~cm}$ in the west-east southern profile (Figure 2). Note that the PS-InSAR displacement at the geothermal power plant indicates a cumulative displacement of less than $3.3 \mathrm{~cm}$. This value likely reflects error during the phase unwrapping procedure rather than real behaviour as the region near the geothermal plant contains sparse coherent PS and SAR acquisitions during the period of maximum deformation. Subsequently, at the geothermal plant, PS-InSAR underestimates the real deformation, as shown in the Comparison between InSAR and levelling section for the levelling observations.

\section{Comparison between InSAR and levelling}

We compare the geodetic PS-InSAR results to the ground levelling measurements at ten sites around the geothermal plant between mid-2013 and 2014 (see Figure 4). The PS-InSAR time series is the result of the mean value of PS-InSAR points within a 50-m 


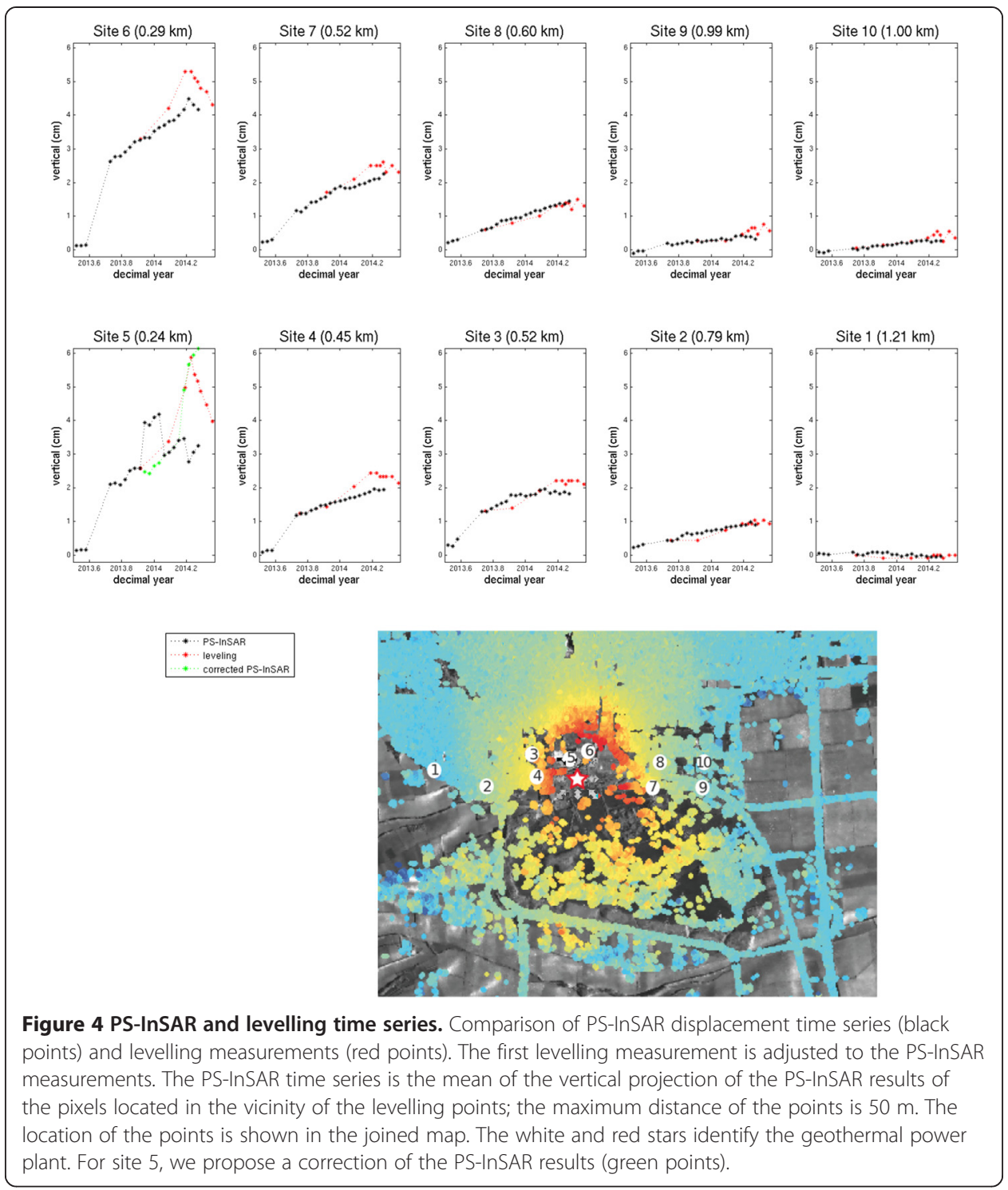

distance. We introduced an arbitrary offset to the first levelling measurement to fit the PS-InSAR estimates of the time series to compare the relative variations between both techniques. The levelling measurements of sites 1 to 4 and site 8 began in 2011, with a second measurement in October 2013. During this time lapse, all of the sites were affected by an uplift that decreased with the distance to the geothermal site. The uplift was 1.7, 1.6, 0.7 and $0.1 \mathrm{~cm}$ for sites 4, 3, 2 and 1, respectively. The difference between the levelling results at these site locations (2011 to 2013) and the InSAR results (April 2012 to September 2013) is less than $0.3 \mathrm{~cm}$. Further, the main displacement before September 2013 arguably occurred during July to September 2013 and could be linked with the geothermal site. The first levelling measurements at the other sites began in October 2013.

Differences between the levelling and PS-InSAR results are typically on the order of a millimetre, except at site 5, where the difference is on the order of a centimetre. An 
excellent agreement is obtained after the offset subtraction for all the sites over the time period.

The displacement is higher close to the power plant and decreases with the distance from the power plant. The maximum of the displacement amplitude for the PS-InSAR measurement is on the eastern side of the power plant at site $6(4.5 \mathrm{~cm})$, and the maximum for the levelling measurements after the offset subtraction (i.e. adjustment to the PS-InSAR results) is on the western side $(5.8 \mathrm{~cm})$. The levelling measurements show that the amplitude of deformation is higher at site 5 and is clearly visible in 2014. Specifically, site 5 is closer to the geothermal plant and affected by higher ground inflation. The PS-InSAR results at site 5 suffers from unwrapping errors, and this is clearly visible in Figure 4, for the dates comprised between 20 December 2013 and 22 January 2014 (four dates); here, the PS-InSAR results are shifted by half a satellite wavelength relative to the previous and following results. We use the levelling results to estimate and correct the phase shift (Figure 4, site 5). We corrected also the four last PS-InSAR results at site 5 of half a satellite wavelength for 7 March 2014 and of one wavelength for the dates between 18 March and 9 April 2014 (three last dates).

At site 6, where the variations in the time series are similar using the two methods, an uplift through mid-March 2014 (2014.2 decimal years) is followed by subsidence. Note that the variation in the amplitude is lower for the PS-InSAR results than for the in situ measurements. At site 5, both the PS-InSAR and levelling methods show uplift from the beginning of the time series to mid-March 2014 (2014.2). After the 24 March levelling measure, the levelling result shows subsidence, whereas the PS-InSAR results show uplift after 18 March 2014.

The difference between the two methods can be attributed to unwrapping errors and/or to the lack of PS-InSAR at the levelling measurement point 5. So the mean of the PSInSAR displacement can result from PS-InSAR with a higher rate of displacement.

\section{A simple model for strain inversion}

We model the surface displacement measured by PS-InSAR between 30 July and 23 September 2013 to evaluate the characteristics of the first period of events. As a starting point, we shall assume that the deformation has a circular shape around the geothermal plant. The displacement measured by levelling and PS-InSAR increases towards the location of the power plant, suggesting a source located below the geothermal plant. The uplift occurs continuously from the onset of the well incident in July 2013, and the subsidence begins when the plant is shut down in March 2013. The surface displacement seems therefore to linearly respond to the behaviour of the deformation source. Accordingly, we suggest that the dominant response underneath the geothermal plant is elastic. We tested two models commonly used in volcano studies: a point source model (Mogi 1958) and an ellipsoidal model (Yang et al. 1988). The displacements modelled by the Mogi point source model can be compared to a displacement induced by the volume variation in a buried spherical cavity with a uniform internal pressure in an elastic half space (McTigue 1987). In this case, the vertical and radial displacements due to a volume variation of the sphere are well known (Mogi 1958; McTigue 1987; Segall 2009). The width of the displacement area is a function of the depth of the source. Its amplitude is a function of the depth and volume of the 
injected fluid. When the depth is fixed, the amplitude is only a function of the volume of injected fluid. We also tested an ellipsoidal model (Yang et al. 1988). The ellipsoidal model is more realistic for modelling the injection of water in sedimentary layers due to the anisotropy characteristic of the sedimentary rocks. The Mogi model has four degrees of freedom: the two horizontal coordinates, the depth and the variation of volume. The elliptical model has eight degrees of freedom. We tested the following six parameters: the two horizontal coordinates, the depth, the pressure and the elliptical parameters (semi-major and semi-minor axes). We have not tested the plunge and the strike angle of the major axis. We fixed the Poisson's ratio value to 0.25 and the Young moduli to $10 \mathrm{GPa}$. We calculated the LOS displacement in the models from the radial and vertical components and compared them to the PS results. We first do a systematic research of the best fitting model, which allows to define the range of possible values for all the parameters. The source location parameters are tested both in the latitude and longitude direction from -180 to $+200 \mathrm{~m}$ within an interval of $50 \mathrm{~m}$. The depth is tested between 200 and $600 \mathrm{~m}$ with an interval of $50 \mathrm{~m}$. The volume variation is tested between 1,000 and $45,000 \mathrm{~m}^{3}$ with an interval of $5,000 \mathrm{~m}^{3}$. In a second step, we do forward modelling using the parameter ranges defined during the first step. Then we look at all the residual maps between the true and synthetic data. We finally select the model showing the minimum residuals around the geothermal site.

We obtain results with a good constraint on the depth, approximately $450 \mathrm{~m}$. The location of the centre of the deformation is also well constrained and is in the vicinity of the geothermal plant (around $\pm 150 \mathrm{~m}$ ).

Figure 5A presents the results of the best fitting Mogi model (blue curve) and Yang model (red curve) along the west-east and north-south profiles with a source at a 450-m depth. The volume variation is $30,000 \mathrm{~m}^{3}$ with the Mogi model. The Yang model produces a pressure change of $10 \mathrm{MPa}$ and elliptical dimensions of 17 and 1,300 m for the semi-minor and semi-major axes, respectively.

Figure 5B represents the residuals between the Mogi model and the PS-InSAR results. The residuals are very small, indicating that the model is in good agreement with the PS-InSAR results, except at the geothermal plant where the phase is not correctly unwrapped. The residuals in the south correspond to an area of Landau with many new buildings, which causes the SAR signal to decorrelate. A circular pattern of deformation remains in the north. This pattern can result from a second source of deformation.

The reinjection well of the Landau power plant is not cemented between depths of 479 and $751 \mathrm{~m}$. A defective joint has already been observed at this well (Ministry of Economic Affairs, Climate Protection, Energy and Regional Planning press talk, 9 April 2014, www. lgb-rlp.de/uploads/media/Pressegespraech-Gelaendeveraenderungen-Landau.pdf). Thus, a geothermal water leakage at a depth of approximately $450 \mathrm{~m}$ is very consistent with our observations.

\section{Conclusions}

The PS-InSAR geodetic measures show that we can distinguish four main periods: 1) First, a continuous uplift north of Landau related to oil field exploitation. 2) In July 2013, a new displacement field appeared south of Landau in the vicinity of the geothermal power plant. This event is clearly visible in the PS-InSAR time series between July 


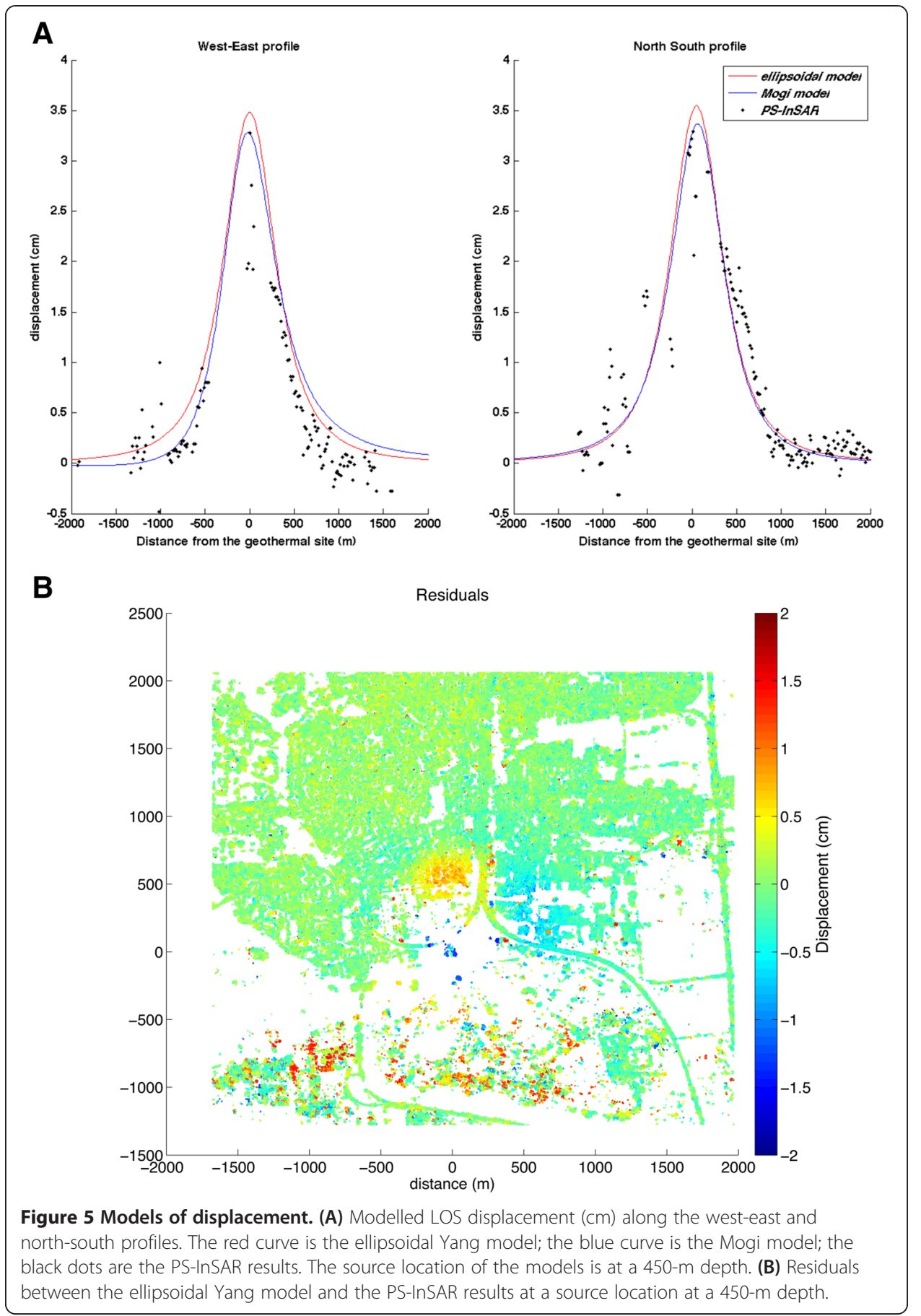

2013 and September 2013. The maximum displacement occurs in this period near the power plant. The amplitude of the displacement decreases with increasing distance from the power plant. 3) The displacement is a multi-centimetre uplift that continues through March 2014. The region of displacement extends up to the centre of the city of Landau. 4) In the last period, from March 2014, we detect subsidence in the vicinity of the geothermal power plant.

Despite the lack of PS-InSAR measurements south of the geothermal power plant owing to the poor coherence of the signal over time, we can assume that the surface 
deformation has a circular pattern around the geothermal power plant. The levelling data show that the maximum displacement is on the east side of the power plant in the drift direction of the reinjection well. This observation is consistent with the origin of the deformation located around the reinjection well and is related to a leakage in the well. The modelling with the Mogi model and the Yang model suggests that this leakage occurs at a depth around $450 \mathrm{~m}$, which is consistent with the existence of a noncemented zone in the reinjection geothermal well.

Our study demonstrates the importance of geodetic monitoring of geothermal power plants. Indeed, geodetic monitoring can help determine the history and the origin of incidents. Moreover, the PS-InSAR method has the ability to delineate the border of the deformed area. However, the PS-InSAR method is unable to provide information on vegetated areas, such as those south of the power plant. Complementary methods, such as levelling and GNSS, are necessary. These complementary methods are also helpful for evaluating the amplitude of the displacement when the displacement between the time lapse and/or adjacent pixels is greater than half of the wavelength of the radar signal. These methods are also necessary for retrieving the vertical and horizontal components of the displacement. In the future, data will be analysed with shorter baselines, and GNSS measurements will contribute to estimating the displacements.

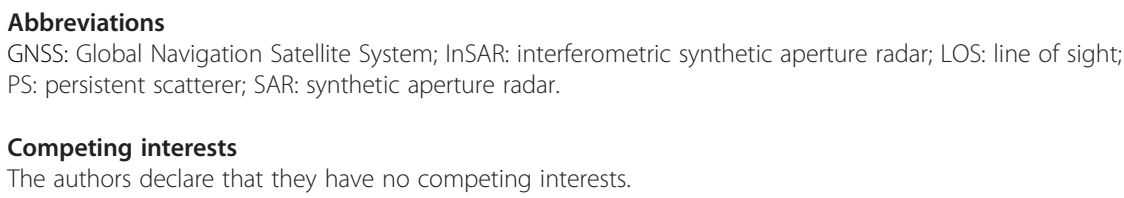
analysis, the interpretation and the figure design. $\mathrm{CH}$ conducted the analysis and interpretation of the levelling measurements. FM, JS, CH and JA conducted the modelling. CH wrote the manuscript, along with contributions from NG, FM and JS. All authors read and approved the final manuscript.

\section{Acknowledgements}

This work has been conducted under the framework of the LABEX ANR-11-LABX-0050_G-EAU-THERMIE-PROFONDE, and it is supported by funding from the state managed by the French National Research Agency as part of the Investments for the Future program. S-W Kim was supported by Global Surveillance Research Center (GSRC) program funded by the Defense Acquisition Program Administration (DAPA) and Agency for Defense Development (ADD). We thank the reviewers for their remarks which greatly improved the manuscript.

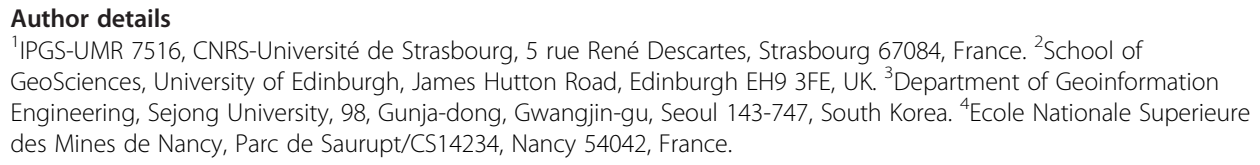


Doubre C, Peltzer G (2007) Fluid-controlled faulting process in the Asal Rift, Djibouti, from 8 yr of radar interferometry observations. Geology 35:69-72

Genter A, Goerke X, Graff JJ, Cuenot N, Krall G, Schindler M, Ravier G (2010) Current status of the EGS Soultz geothermal project (France). In: World Geothermal Congress, WGC2010, Bali, Indonesia, 2010, 25-29 April

Gerard A, Genter A, Kohl T, Lutz P, Rose P, Rummel F (2006) The deep EGS (Enhanced Geothermal System) project at Soultz-sous-Forêts (Alsace, France). Geothermics 35:473-483

Farr TG Rosen PA, Caro E, Crippen R, Duren R, Hensley S, Kobrick M, Paller M, Rodriguez E, Roth L, Seal D, Shaffer S, Shimada J, Umland J, Werner M, Oskin M, Burbank D, Alsdorf D (2007) The Shuttle Radar Topography Mission. Rev Geophys 45. doi:10.1029/2005RG000183

Ferretti A, Prati C, Rocca F (2001) Permanent scatterers in SAR interferometry. IEEE Trans Geosci Rem Sens 39:8-20

Fialko Y, Sandwell D, Simons M, Rosen P (2005) Three-dimensional deformation caused by the Bam, Iran, earthquake and the origin of shallow slip deficit. Nature 435:295-299

Fialko Y, Simons M (2000) Deformation and seismicity in the Coso geothermal area, Inyo County, California: observations and modeling using satellite radar interferometry. J Geophys Res-Solid Earth 105:21781-21793

Gabriel AK, Goldstein RM, Zebker HA (1989) Mapping small elevation changes over large areas - differential radar interferometry. J Geophys Res-Solid Earth Planets 94:9183-9191

Glowacka E, Sarychikhina O, Suarez F, Nava FA, Mellors R (2010) Anthropogenic subsidence in the Mexicali Valley, Baja California, Mexico, and slip on the Saltillo fault. Environ Earth Sci 59:1515-1524

Gourmelen N, Amelung F, Casu F, Manzo M, Lanari R (2007) Mining-related ground deformation in Crescent Valley, Nevada: implications for sparse GPS networks. Geophys Res Lett 34, L09309

Hanssen, R (2001) Radar interferometry: data interpretation and error analysis. Kluwer Academic Publishers, Dordrecht

Hooper A, H Zebker, P Segall, B Kampes (2004) A new method for measuring deformation on volcanoes and other natural terrains using InSAR persistent scatterers. Geophys Res Lett 31, L23611. doi: 10.1029/2004GL021737

Jeanne P, Rutqvist J, Vasco D, Garcia J, Dobson PF, Walters M, Hartline C, Borgia A (2014) A 3D hydrogeological and geomechanical model of an Enhanced Geothermal System at The Geysers, California. Geothermics 51:240-252

Jonsson S, Adam N, Bjornsson H (1998) Effects of subglacial geothermal activity observed by satellite radar interferometry. Geophys Res Lett 25:1059-1062

Kim S-W, Wdowinski S, Amelung F, Dixon T, Won S-J, Kim J-W (2010) Measurements and predictions of subsidence induced by soil consolidation using permanent scatterer InSAR and hyperbolic model. Geophys Res Lett V 37, L05304. doi:10.1029/2009GL041644

Lubitz C, Motagh M, Wetzel H-U, Kaufmann K (2013) Remarkable urban uplift in Staufen im Breisgau, Germany: observations from TerraSAR-X InSAR and leveling from 2008 to 2011. Remote Sens 5:3082-3100

McTigue DF (1987) Elastic stress and deformation near a finite spherical magma body: resolution of the point source paradox. J Geophys Res 92:12,931-12,940

Massonnet D, Feigl KL (1998) Radar interferometry and its application to changes in the Earth's surface. Rev Geophys 36:441-500

Massonnet D, Holzer T, Vadon H (1997) Land subsidence caused by the East Mesa geothermal field, California, observed using SAR interferometry. Geophys Res Lett 24:901-904

Massonnet D, Rossi M, Carmona C, Adragna F, Peltzer G, Feigl K, Rabaute T (1993) The displacement field of the Landers earthquake mapped by radar interferometry. Nature 364:138-142

Mogi K (1958) Relations between the eruptions of various volcanoes and the deformations of the ground surfaces around them. Bull Earthquake Res Inst Univ Tokyo 36:99-134

Newman AV, Dixon TH, Gourmelen N (2006) A four-dimensional viscoelastic deformation model for Long Valley Caldera, California, between 1995 and 2000. J Volcanol Geotherm Res 150:244-269

Nishijima J, Fujimitsu Y, Ehara S, Kouno E, Yamauchi M (2005) Micro-gravity monitoring and repeated GPS survey at Hatchobaru geothermal field, central Kyushu, Japan. In: Proceedings World Geothermal Congress, Antalya, Turkey, 24-29 April 2005

Peltzer G, Crampe F, Hensley S, Rosen P (2001) Transient strain accumulation and fault interaction in the Eastern California shear zone. Geology 29:975-978

Pribnow D, Schellschmidt R (2000) Thermal tracking of upper crustal fluid flow in the Rhine Graben. Geophys Res Lett 27(13):1957-1960

Pritchard ME, Simons M (2002) A satellite geodetic survey of large-scale deformation of volcanic centres in the central Andes. Nature 418:167-171

Rosen PA, Hensley S, Joughin IR, Li FK, Madsen SN, Rodriguez E, Goldstein RM (2000) Synthetic aperture radar interferometry. Invited paper, Proc IEEE 88:333-382

Segall P (2009) Earthquake and volcano deformation. Princeton University Press, Princeton

Usai S (1997) The use of man-made features for long time scale INSAR. In: Geoscience and Remote Sensing, 1997. IGARSS '97. Remote Sensing - A Scientific Vision for Sustainable Development. 1997 IEEE International. 4:1542:1544. 3-8 Aug 1997. doi: 10.1109/IGARSS.1997.608936.

Vasco DW, Ferretti A, Novali F (2008) Reservoir monitoring and characterization using satellite geodetic data: interferometric synthetic aperture radar observations from the Krechba field, Algeria. Geophysics 73(6):WA113-WA122

Wicks CW, Thatcher W, Dzurisin D, Svarc J (2006) Uplift, thermal unrest and magma intrusion at Yellowstone caldera. Nature 440:72-75

Wright TJ, Ebinger C, Biggs J, Ayele A, Yirgu G, Keir D, Stork A (2006) Magma-maintained rift segmentation at continental rupture in the 2005 Afar dyking episode. Nature 442:291-294

Yang XM, Davis PM, Dietrich JH (1988) Deformation from inflation of a dipping finite prolate spheroid in an elastic half-space as a model for volcanic stressing. J Geophys Res 93(B5):4249-4257

Zebker HA, Rosen PA, Goldstein RM, Gabriel A, Werner CL (1994) On the derivation of coseismic displacement-fields using differential radar interferometry - the Landers earthquake. J Geophys Res-Solid Earth 99:19617-19634 